\title{
Recall and recognition of words and pictures by adults and children
}

\author{
MARILYN A. BORGES, MARY ANN STEPNOWSKY, and LELAND H. HOLT \\ San Diego State University, San Diego, California 92182
}

\begin{abstract}
Recall and recognition performance were compared under three different modes of presentation (written words, black-and-white pictures of objects, and color pictures of objects) for 30 subjects in each of three grade levels (college students, sixth graders, and fourth graders). The results showed a developmental trend of increasing recall performance' with age. Whereas adult performance was significantly affected by mode of presentation (color pictures $>$ black-and-white pictures $>$ written words), no difference was found across presentation modes for the fourth and sixth graders. However, the data also indicated that children do have pictorial and color cues available in memory in a manner very similar to adults. It was suggested that the cognitive structures of children do not utilize this stimulus information.
\end{abstract}

In recent years it has become generally accepted that recall of pictorial stimuli is superior to that of word stimuli. A number of experiments using adult subjects (e.g., Paivio \& Yarmey, 1966; Rowe, 1973; Rowe \& Paivio, 1971) have supported this assertion. However, the data for children are not as extensive, and the results have been mixed. Ducharme and Fraisse (1965) found that, for 8-year-old children, words were slightly easier to memorize than pictures. Cole, Frankel, and Sharp (1971) reported that children of all ages from 6 through 15 showed greater recall for pictures than for words. Thus, the data available seem to suggest that the word-picture relationship may not be the same for both children and adults.

A smaller number of experiments have investigated the influence of color on the recall of pictures. Paivio and Yarmey (1966) and Paivio, Rogers, and Smythe (1968) reported no significant difference between color and black-and-white presentations. However, Bousfield, Esterson, and Whitmarsh (1957) found that recall of words plus colored pictures was superior to words plus uncolored pictures, and that recall for both conditions was superior to that of words alone.

The purpose of the present study was to examine these word vs. picture and color vs. no-color relationships for both children and adults.

\section{METHOD}

A 2 by 3 by 3 (sex by grade level by mode of presentation) factorial design was used, with Mode of Presentation as a withinsubject factor. Recall and recognition performance was compared for 15 males and 15 females in each of three grade levels: college, sixth grade, and fourth grade. The three presentation

The authors acknowledge the valuable assistance of Sylvia G. Montejano in collecting the data. Requests for reprints should be sent to Marilyn A. Borges, Department of Psychology, San Diego State University, San Diego, California 92182. modes were names of objects (in cursive writing), black-andwhite photographs of the objects, and color photographs of the same objects.

The presentation items were 30 concrete nouns with a frequency count of at least 11 per million (Thorndike-Lorge, 1944). Three different presentation lists were constructed, each containing the 30 items on slides, 10 in each of the three presentation modes. One-third of each grade-level group was shown one of the three slide presentations. The slides were shown for $3 \mathrm{sec}$ with an intertrial interval of approximately $.5 \mathrm{sec}$. The subjects were informed prior to the slide presentation that they would be asked to later recall the list of items.

Following the slide presentations, the subjects wrote down as many items as they could remember. A four-alternative (new item, old item: written word, color picture, black-andwhite picture) recognition test on the 30 old items and 30 new items in printed-word form was given $10 \mathrm{~min}$ after the slide presentations ceased. The subjects' task was to decide if each printed item had appeared before in one of the three presentation modes. Individual recall- and recognition-test termination times were subject determined.

The recognition data was analyzed within the framework of signal detection theory and scored in two ways. First, the presented words that were marked as seen (old words) in any mode of presentation were scored as correct. Second, the number of words marked as seen in only the correct mode of presentation were scored as correct. These two "hit" scores, together with the false alarm scores, were converted into two $d^{\prime}$ values for each subject.

\section{RESULTS AND DISCUSSION}

An analysis of variance performed on the recall data indicated that females recalled more than males $[\mathrm{F}(1,84)=6.56]$ and that recall increased with age $[\mathrm{F}(2,84)=3.36]$ and across modes of presentation $[F(2,168)=6.56$, all ps $<.05]$. However, further tests on the only significant interaction, Grade by Mode of Presentation $[F(4,168)=3.00]$, indicated that, while mean recall increased with age, only college students' recall was affected by mode of presentation $(\overline{\mathrm{X}}=6.7$ color pictures $>5.8$ black-and-white pictures $>5.0$ written words, all ps $<.05$ ). Mode of presentation had 
no effect on sixth and fourth graders $(\overline{\mathrm{X}}=5.9,5.3$, $5.9 ; 5.5,5.3,4.6$, respectively).

An analysis of variance performed on the $d^{\prime}$ recognition data which ignored presentation mode correctness showed only Mode of Presentation $[F(2,168)=$ 7.63] and Grade Level by Mode of Presentation $[F(4,168)=5.06]$ to be significant variables (both ps $<.001)$. Further tests showed that, while total recognition tended to increase with age, again, only college students were affected by mode of presentation $\left(\overline{\mathrm{X}} \mathrm{d}^{\prime}=\mathbf{3 . 4}\right.$ for color pictures $>3.0$ for black-and-white pictures $>2.4$ for written words). Mean d' for sixth and fourth graders $=2.9,2.9,2.9 ; 2.4,2.4,2.3$, respectively.

An analysis of variance performed on the correct mode recognition data showed a significant effect for Grade Level $[F(2,84)=3.13]$, Mode of Presentation $[\mathrm{F}(2,168)=21.40]$, and Grade Level by Mode of Presentation $[F(4,108)=4.14$, all ps $<.05]$. Further tests on the $\mathrm{d}^{\prime}$ means and on the percentage of presented items correctly identified by presentation mode gave the same results. All grade levels identified more color pictures $(\overline{\mathrm{X}}=64 \%)$ and written words $(\overline{\mathrm{X}}=71 \%)$ in their correct mode of presentation than black-and-white pictures $(\bar{X}=47 \%)$. The only exceptions were fourth graders whose recognition of color pictures $(\overline{\mathrm{X}}=52 \%)$ was only slightly above that of black-and-white pictures $(\overline{\mathrm{X}}=41 \%)$.

The particular types of mode-identification were also analyzed. All grade levels were found to make approximately the same basic number and type of errors on identifying the presented list items. Few errors were made confusing pictures and words, but color pictures and black-and-white pictures were often confused (picture to word: $2 \%, 2 \%, 6 \%$; word to picture: $7 \%$, 3\%, $8 \%$; color to black-and-white: $20 \%, 21 \%, 25 \%$; black-and-white to color: $37 \%, 38 \%, 35 \%$, for adults, sixth graders, and fourth graders, respectively).

The fact that fourth and sixth graders were similar to college students in the number and type of errors made in mode identification of the presented items suggests that children at these ages do have both pictorial and color information encoded. Neither the Ducharme and Fraisse (1965) suggestion that children tend not to label pictures as adults do, nor the suggestion that children use uniquely idiosyncratic labels is consistent with the present results in which adults and children made similar qualitative and quantitative errors in mode identification of pictorial stimuli.

Thus, the results that both color and pictorial cues enhanced the recall and old-new recognition performance of adults, but not of fourth and sixth graders, cannot be attributed to differences in the encoding or processing of such cues that change with age. More likely, the differential memory-mode performance of adults was due to their more strategic and effective use of these encoded cues. For adults, the greater the number of feature cues describing each stimulus item (labels, pictorial cues, color cues, etc.), the greater their ability to retrieve or access each item for recall or recognition. For children, each new item that was presented had the same probability of being remembered, regardless of the number or type of feature cues that could have distinguished that item from some others. Evidently, college students have, perhaps through pragmatic necessity or intellectual development, learned to effectively use these encoded feature cues to enhance their recall and recognition performance.

\section{REFERENCES}

Bousfield, W. A., Esterson, J., \& Whitmarsh, G. A. The effects of concomitant colored and uncolored pictorial representations on the learning of stimulus words. Journal of Applied Psychology, 1957, 41, 165-168.

Cole, M., Frankel, F., \& Sharp, D. Development of free recall learning in children. Developmental Psychology, 1971, 4, 109-123.

Ducharme, R., \& Fraisse, P. Etude genetique de la memorisation de mots et d'images. Canadian Journal of Psychology, 1965, 19, 253-261.

Paivio, A., Rogers, T. B., \& Smythe, P. C. Why are pictures easier to recall than words? Psychonomic Science, 1968, 11, 137-138.

Paivio, A., \& YARMey, A. D. Pictures versus words as stimuli and responses in paired-associate learning. Psychonomic Science, 1966, 5, 235-236.

RowE, E. J. Verbalization effects in discrimination learning of pictures and words. Canadian Journal of Psychology, 1973, 27, 184-188.

Rowe, E. J., \& Parvio, A. Discrimination learning of pictures and words. Psychonomic Science, 1971, 22, 87-88.

THORNDIKE, E. L., \& LORGE, I. The teacher's word book of 30,000 words. New York: Teacher's College, Columbia University, 1944.

(Received for publication September 24, 1976.) 